\title{
Thermo-protective properties of polymer composites with nano-titanium dioxide
}

\author{
Sylwester Stawarz $\mathbb{D}$ - Natalia Witek • Wojciech Kucharczyk • Mohamed Bakar • \\ Magdalena Stawarz
}

Received: 29 October 2018/Accepted: 15 November 2018/Published online: 6 December 2018

(C) The Author(s) 2018

\begin{abstract}
The present work investigates the ablative and thermal properties of an epoxy resin which was modified with titanium dioxide nanoparticles having different size. Prepared samples were submitted to temperatures above $1900{ }^{\circ} \mathrm{C}$ and tested for their thermo-protective and ablative properties. The effect of epoxy composite components on thermo-protective and ablative properties: the maximum back side temperature, and the average weight loss under intensive heat flow conditions as well as temperature distribution on the ablation surface of the sample using a thermographic camera and a pyrometer have been established. A statistical analysis of the test results was made. It was confirmed that epoxy resin crosslinked with polyaminoamide hardener and modified with $\mathrm{TiO}_{2(21 \mathrm{~nm})}$ i $\mathrm{TiO}_{2(100 \mathrm{~nm}+1 \% \mathrm{Mn})}$ showed improved thermo-protective properties in comparison with unmodified epoxy matrix.
\end{abstract}

S. Stawarz $(\bowtie) \cdot$ N. Witek · W. Kucharczyk ·

M. Stawarz

Faculty of Mechanical Engineering, Kazimierz Pulaski

University of Technology and Humanities in Radom,

Radom, Poland

e-mail: stawarz@uthrad.pl

\section{Bakar}

Faculty of Materials Science, Technology and Design, Kazimierz Pulaski University of Technology and

Humanities, Radom, Poland
Keywords Epoxy nanocomposites - Ablative properties - Thermal resistance

\section{Introduction}

Ablation is a self-regulating process of heat and mass exchange leading to occurrence of physical changes and chemical reactions, irreversible structural and chemical changes of the material with the simultaneous heat absorption. This process is initiated and sustained from external sources of thermal energy. The thermal decomposition in the initial phase of the ablation process and the pyrolysis reactions at a higher temperature leads to the formation of a porous carbon layer with a very low thermal conductivity coefficient (so-called ablative layer) up to $2 / 3$ of the initial matrix weight (Lin 2005; Yu 2004; Dimitrienko 1997).

The term ablation refers to the exchange of heat and mass in the body's upper layer in thermochemical and mechanical processes. There are many technical applications for ablative material. Polymeric ablation materials are increasingly used in the field of thermal protection systems. They can be used in the design of passive refractories for load-bearing structures of large-size buildings (NIST NCSTAR 1 2005; Wilkinson 2002), communication tunnels (Haack 2004; Ono and Otsuka 2006) and for protection of data stored on electronic, optical, magnetic, etc. 
Modeling ablative thermo-protective properties consists in the selection of materials with high specific heat $c_{p}(t)$ and high density $\rho$, high thermal capacity and with low thermal conductivity coefficient $\lambda(t)$ (i.e. small thermal diffusivity $\alpha(t)$ ) (Kucharczyk 2007; Song et al. 2003a, b). In polymeric composites, when the ablation temperature $T_{a}$ is exceeded, there are endothermic reactions related to the thermal decomposition of the matrix material, which results in effective specific heat $c_{p}$ with high values. In their pure form, polymers are good ablative materials (Bahramian and Kokabi 2009; Bakar et al. 2016) with a very low heat conduction coefficient $\lambda$. However, due to their softening, low density and low thermal stability as well as the porosity and brittleness of the ablative layer formed in the ablation process, they need to be modified with mineral fillers (Bahramian and Kokabi 2009; Lombardi et al. 2012) or reinforcing fibers (Jackowski 1986; Bahramian 2013; Kucharczyk 2012; Patton et al. 2002) increasing their thermal stability, resistance to heat flow, and consequently the thermal insulation of the composite.

Epoxy composites and specific shells will protect machines, devices, components of building structures and people during incidental thermal loads much higher than expected, when the temperature increase, e.g. of carbon steel above $800{ }^{\circ} \mathrm{C}$, can cause a sixfoldeightfold decrease in its tensile strength and almost twice reducing its stiffness. Classical refractory materials do not protect against the temperature increase on the back surfaces of the protective layers as effectively as polymeric ablation materials, whose high thermal resistance of $r_{k p}\left(\mathrm{~m}^{2} \mathrm{~K} / \mathrm{W}\right)$, allows to reduce the temperature in the range from several dozen degrees to $2000{ }^{\circ} \mathrm{C}$, with the use of insulating walls of small thickness (Kucharczyk et al. 2018).

Ablative screens can also protect stored data of electronic, optical, magnetic carriers, etc. Classic materials and fire-fighting systems do not provide this possibility, because in emergency situations even rapid fire suppression does not reduce the heat transfer through the protective wall to the extent that it does not exceed the allowed operating temperature of the data carrier (Kucharczyk 2010).

Recently, attempts have been made to obtain hybrid composites based on epoxy resins that contain two different modifiers. An important advantage of hybrid materials is a unique combination of mechanisms for properties improvement which may lead to synergistic effect unrealizable with traditional composites with one modifier (Bakar et al. 2014; Szymanska et al. 2017). Due to the ease of processing and fairly good physical properties, there is an increasing interest in using not only thermoplastics but also thermosetting plastics as matrix for composite materials (Kucharczyk et al. 2013; Bakar et al. 2010, Szymanska et al. 2017).

The investigation of such materials is particularly important for the researchers and industrialists, because it is in connection with the existing terrorist threat. This subject is becoming more and more important and was included in the NATO-DAT (Defense Against Terrorism) program. Based on the analysis of the effects of terrorist attacks in Oklahoma City, on the World Trade Center (NIST NCSTAR 1 2005; Wilkinson 2002), the behavior of this type of materials is tested and analyzed using computer programs (Willam et al. 2004). These materials are beginning to be used in the protection of few but important public utilities. Despite many years of use of ablative materials, there are still unexplored qualitative and quantitative relationships between the indicated type-phase composition and thermo-protecting properties of composites.

Conducting research will develop hypotheses for the preparation of polymer ablation composites to protect people, machines, devices and load-bearing construction structures against short-term exposure to high temperature flux, as well as to describe the quantitative and qualitative impact of epoxy modifiers on the ablation process and their selected strength properties.

The results of the work can be application-oriented, form the basis for the design of thermal shields, especially for the protection of civil structures, and can be a preliminary stage for designing structures and developing technologies for modern aviation components with such systems.

The purpose of the present study was to determine the effect of nanoparticles on the ablative properties, i.e. the maximum temperature of the rear surface area $T_{S_{\_} \max }$ and ablative weight loss $U_{a}$ of epoxy composites containing two $\mathrm{TiO}_{2}$ nanoparticles with different particles size $(21 \mathrm{~nm}$ and $100 \mathrm{~nm})$. Prepared epoxy nanocomposites have to be used as thermal protective surfaces in machines and equipments. 


\section{Evaluation of ablative properties}

The research works was carried out based on a developed research plan as follows:

1. Material samples were made for classical, thermoprotective ablative tests.

2. A classic ablation study was carried out using the effects of high temperature heat flux.

3. The effect of components on erosive and ablative material wear as well as the temperature of the back surface of the sample wall of the tested composites in classical ablation tests was assessed.

4. A statistical analysis of the test results was made.

5. Probable reasons for the interaction between the epoxy composites components and the possibilities of thermo-protective protection of the structures were discussed and established.

The so-called "ablative gun" (Song et al. 2003a, b) of our own design (Kucharczyk 2007) was used or the classical ablation tests of thermo protective properties, allowing the effect of high temperature, stabilized, homogeneous flammable gas stream on the sample. The temperature distributions was recorded on the ablation surfaces and the back surfaces of the sample walls by using the available pyrometers, thermovision camera and thermocouples. Ablation weight loss were determined.

The research on ablation properties of thermo protective hybrid epoxy nanocomposites, was carried out on the basis of the developed statistical program of the first-order type $2^{3}$ experimental test with repetitions (Montgomery 2009; Leszek 1997).

\subsection{Materials used for epoxy-nanocomposites preparation}

Considering the differences of some specific physicochemical, technological and performance properties, ease of processing, production costs, availability of components as well as results of literature analysis, epoxy nanocomposites modified with titanium dioxide nanoparticles were selected for the study.

A liquid epoxy resin Epidian 52 produced by Sarzyna Chemical Company (Nowa Sarzyna, Poland) was chosen as a matrix for nanocomposites. It is a mixture of a low-molecular diglycidyl ether of Bisphenol A and an active diluent which reacts with the hardener during the epoxy resin curing process (Czub et al. 2002).

A polyaminoamide hardener with the trade name PAC produced by ZCh Ciech-Sarzyna in Nowa Sarzyna (Table 1) was used as crosslinking agent.

The hardener (PAC) is mainly used for the modification and curing of low molecular weight epoxy resin. It is a low-reactive, viscous liquid that can be used in a wide range of weight ratios. The lifetime of the epoxy composition with PAC hardener is several hours, and complete curing takes place within 4-7 days.

Two types of titanium nanodioxide (Sigma-Aldrich Co 2014) were selected to modify the epoxy matrix:

- molecular weight: $79.87 \mathrm{~g} / \mathrm{mol}$;

- density at $25{ }^{\circ} \mathrm{C}: 4.26 \mathrm{~g} / \mathrm{cm}^{3}$;

- $\mathrm{pH}=5-8.5$;

- melting point: $1250{ }^{\circ} \mathrm{C}$;

- particle size: $\mathrm{TiO}_{2(21 \mathrm{~nm})} 21 \mathrm{~nm}$ and $\mathrm{TiO}_{2}$

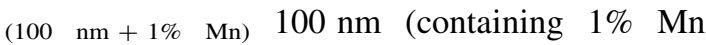
additive).

Titanium oxide exists in many types of rocks and minerals in three crystalline forms, as rutile, anatase or brookite. It is the ninth most common element in the Earth's crust. Additionally, it absorbs UV rays in the range of $290-400 \mathrm{~nm}$ and is usually considered as chemically inert (Anselme 2013; Bowers 2012) (Fig. 1).

The titanium oxide in the nano form with particles have a size less than $100 \mathrm{~nm}$ has been selected in the present study. The particles are strongly bound or connected with each other by means of chemical bonds, forming aggregates, i.e. particles of micro scale size (Anselme 2013).

Titanium dioxide is characterized by: high refractive index in the range of 2.616-2.903 (higher than for diamond); low optical absorption in the visible range; good chemical stability; high chemical resistance; high hardness of about 6 on the Mohs scale; high permeability (120 for rutile); high resistance (SigmaAldrich Co 2014).

Titanium dioxide has been used for several decades in many industries, including in the production of fibers, printing inks, adhesives, varnishes, rubber composites, LCD screens, self-cleaning glass and ceramics, antibacterial materials, resistant to UV rays and conductive, food packaging, air and sewage treatment processes, and also in the metallurgical 
Table 1 Epoxy resin and curing agent characteristics (Ciech-Sarzyna Co 2014)

\begin{tabular}{ll}
\hline Resin-Epidian 52 & Curing agent-PAC \\
\hline Average molecular weight of $700 \mathrm{~g} / \mathrm{mol}$ & $\mathrm{pH}=12.3$ \\
Melting temperature (cured): $150{ }^{\circ} \mathrm{C}$ & No boiling (temp. $\left.>250{ }^{\circ} \mathrm{C}\right)$ \\
Density $\left(20{ }^{\circ} \mathrm{C}\right): 1.12 \mathrm{~g} / \mathrm{cm}^{3}$ & Coagulation temperature: $3-4{ }^{\circ} \mathrm{C}$ \\
Viscosity $\left(25^{\circ} \mathrm{C}\right): 400-800 \mathrm{~m} \mathrm{~Pa} \mathrm{~s}$ & Density $\left(20^{\circ} \mathrm{C}\right): 1.10-1.20 \mathrm{~g} / \mathrm{cm}^{3}$ \\
Ignition temperature: $64{ }^{\circ} \mathrm{C}$ & Viscosity $\left(25^{\circ} \mathrm{C}\right): 10,000-25,000 \mathrm{~m} \mathrm{~Pa} \mathrm{~s}$ \\
& Ignition temperature: $\sim 170{ }^{\circ} \mathrm{C}$ \\
\hline
\end{tabular}
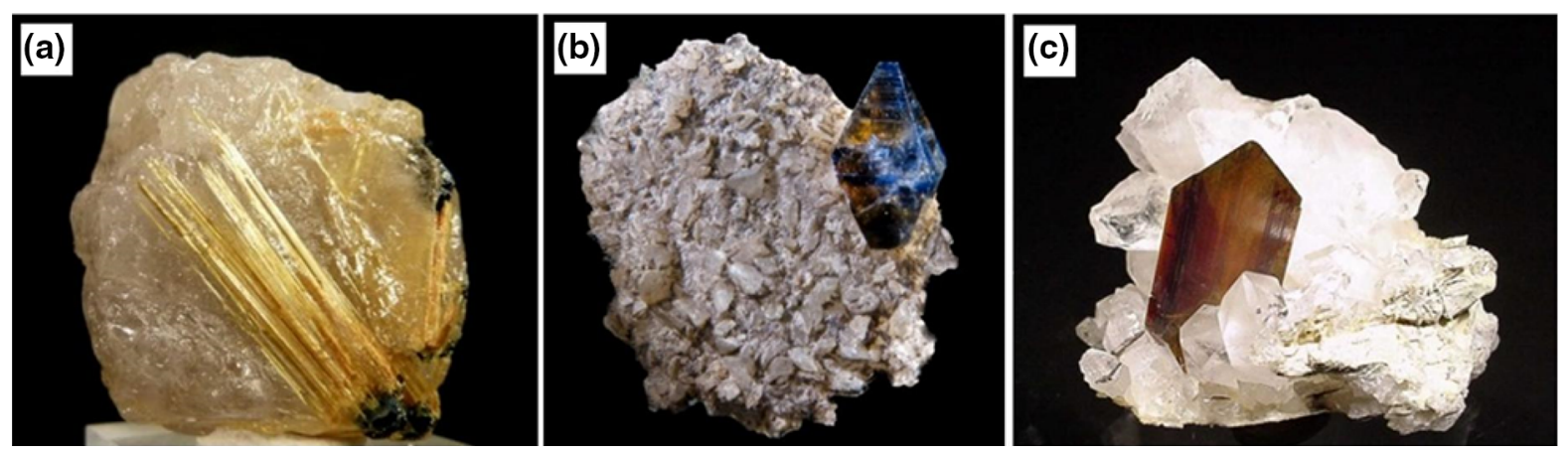

Fig. 1 Titanium oxide crystalline forms: a rutile, b anatase, c brookite (Anselme 2013; Bowers 2012)

and aerospace industries and cosmonautic (Rao Rao et al. 2012; Fujishima and Zhang 2006; Hu et al. 2003; Li et al. 2003).

Titanium dioxide in the nano scale is characterized by significantly better properties and a wider range of use compared to standard titanium oxide.

Al-Ajaj et al. (2013) as well as Rajabi et al. (2013) conducted research on the effect of titanium dioxide on the properties of epoxy resin. Both research groups have shown that the use of titanium dioxide nanoparticles increases the flexural strength, Young's modulus and resistance to cracking as well as an the glass transition temperature. This is caused by a reduction in the distance between the nanofillers and the polymer chain, the polarity of the particles, the strength of the van der Waals bonds in the matrix and the length of the polymer chains, as confirmed by Merad et al. (2011), Hsieh et al. (2010). However, Chen and Mao (2007) and Chatterjee and Islam (2008) and their research groups showed that, the stiffness of the epoxy composite increases with increasing content of the nanofillers. This is mainly attributed to the increased limitations of the polymer chains movement due to the presence of solid particles.

In addition, Chatterjee et al. showed significantly improvement in the thermal, mechanical and viscoelastic properties of the epoxy resin with the addition of titanium dioxide nanoparticles. Chang et al. (2005) investigated the effect of the addition of titanium dioxide on the tribological properties of epoxy resin. They showed that a small amount of the nanofiller visibly reduces the coefficient of friction. Wetzel et al. (2006) modified epoxy resin by using titanium dioxide and aluminum oxide nanoparticles. The controlled dispersion process was obtained by using high energy process to reduce the size of agglomerates and to obtain a homogeneous distribution of individual nanoparticles in the resin. They observed different fracture mechanisms such as crack deflection, plastic deformation, and crack pinning due to the presence of the nanoparticles in epoxy composites.

\subsection{Experimental research plan}

The number of sample phase compositions, equal to the number of scheduled experiments $(N=8)$, was determined on the basis of the experiment plan described by an orthogonal 1st order full-factorial matrix of the type $2^{3}$ (Table 2). It included single replications, where two state levels (lower level -1 and upper level +1 ) and three independent input 
Table 2 Full-factorial planning matrix type $2^{3}$ with repetition (Montgomery 2009; Leszek 1997)

\begin{tabular}{llllllllll}
\hline$j$ & $x_{o}$ & $x_{1}$ & $x_{2}$ & $x_{3}$ & $x_{1} x_{2}$ & $x_{1} x_{3}$ & $x_{2} x_{3}$ & $x_{1} x_{2} x_{3}$ & $\bar{y}$ \\
\hline 1 & + & - & - & - & + & + & + & - & \\
2 & + & + & - & - & - & - & + & + & \\
3 & + & - & + & - & - & + & - & + & \\
4 & + & + & + & - & + & - & - & - & \\
5 & + & - & - & + & + & - & - & + & \\
6 & + & + & - & + & - & + & - & - & \\
7 & + & - & + & + & - & - & + & - & \\
8 & + & + & + & + & + & + & + & + & \\
& $b_{0}$ & $b_{1}$ & $b_{2}$ & $b_{3}$ & $b_{12}$ & $b_{13}$ & $b_{23}$ & $b_{123}$ & \\
\hline
\end{tabular}

variables $\left(x_{\mathrm{i}}\right)(i=1,2,3)$ occur (Montgomery 2009; Leszek 1997):

$x_{1}$ - amount of PAC hardener relative to Epidian 52 resin

([phr] - number of parts by weight of the hardener per 100 parts of resin)

$$
\begin{aligned}
& (-) \quad 60 \quad \mathrm{i}(+) 100, \quad x_{1(s ́ r)}=80, \\
& \Delta x_{1}=20 ;
\end{aligned}
$$

$x_{2}-$ volume fraction of the mixture of both $\mathrm{TiO}_{2}$ nanofillers in the composite [\%]

$$
\begin{aligned}
& (-) 2 \% \text { i (+) } 5 \%, \quad x_{2(s r)}=3.5 \%, \\
& \Delta x_{2}=1.5 \% ;
\end{aligned}
$$

$x_{3}$ - weight fraction of $\mathrm{TiO}_{2(21 \mathrm{~nm})}$ to the sum of the weight of both nanofillers

$$
\begin{aligned}
& \mathrm{TiO}_{2(21 \mathrm{~nm})} /\left[\mathrm{TiO}_{2(100 \mathrm{~nm}}+1 \% \mathrm{Mn}\right) \\
& \mathrm{nm})],[\%], \\
& (-) 60 \% \text { i } \mathrm{TiO}_{2(21}- \\
& \Delta x_{2}=15 \% .
\end{aligned}
$$

The components of the response variable $y$ (the output parameters) are the average maximal temperature of the rear surface of specimen $T_{s_{-} \max }\left({ }^{\circ} \mathrm{C}\right)$ and an average relative ablative (erosive) weight loss $U_{a}(\%)$ after $120 \mathrm{~s}$ of treatment with hot combustion gases.

The regression and interaction coefficients $\left(b_{i}\right)$ of all function components have been calculated. The statistical analysis of the results enabled to determine the threshold relevance of the regression coefficients $\left(b_{i}\right)$ and estimation of their effect on the output parameters $(y)$. The output value was calculated from the following equation of the experiment objective (1) (Montgomery 2009; Leszek 1997):

$$
\begin{aligned}
y= & \left(b_{0}+b_{1} x_{1}+b_{2} x_{2}+b_{3} x_{3}+b_{12} x_{1} x_{2}\right. \\
& \left.+b_{13} x_{1} x_{3}+b_{23} x_{2} x_{3}+b_{123} x_{1} x_{2} x_{3}\right) \pm s(y)
\end{aligned}
$$

Moreover, the variance $s(y)$, regression error and interaction coefficients $s\left(b_{i}\right)$, as well as the level of their statistical significance $\left(b_{\text {sign }} \geq b_{i}\right)$ have been determined on the basis of t-Student test at the confidence level $\alpha_{\mathrm{p}}=0.05$ (Montgomery 2009; Leszek 1997).

\subsection{Samples preparation}

The polymer matrix of the composite samples was Epidian 52 epoxy resin, cross-linked at room temperature with PAC hardener during 14 days. The ablation properties of the resins were modified by adding high density bulk nanofillers (titanium dioxide with a grain size of $21 \mathrm{~nm}$ and $100 \mathrm{~nm}$ ).

The weight fraction of the hardener $\left(x_{1}\right)$ and the content of powder fillers ( $x_{2}$ - the volume fraction of the mixture of both fillers in the composite and $x_{3}$-the weight fraction of $\mathrm{TiO}_{2(21 \mathrm{~nm})}$ in the total weight of both nanofillers) were independent variables of the Type I test plan with repetition and were presented using an orthogonal full-matrix matrix. The weight compositions of the obtained composites are summarized in Table 3 .

The epoxy composite samples were prepared as follows:

- appropriate amount of $\mathrm{TiO}_{2}(21 \mathrm{~nm})$ was added to epoxy resin Epidian 52 and mixing of ingredients was carried out by using a Hielscher UP200H homogenizer (cycle: 1, amplitude: 100\%) during $15 \mathrm{~min}$;

- addition of a second nanofiller $\left.\mathrm{TiO}_{2(100 \mathrm{~nm}}+1 \% \mathrm{Mn}\right)$ to the mixture;

- mixing of ingredients using homogenizer during additional $15 \mathrm{~min}$;

- cooling of obtained mixture to room temperature;

- addition of the curing agent;

- mechanical mixing of obtained composite for $5 \mathrm{~min}$;

- pouring the mixture into previously prepared forms;

- curing of samples at room temperature during 14 days. 
Table 3 The mass phase compositions of the composites

\begin{tabular}{lllllllll}
\hline No. & $\mathrm{x}_{1}$ & $\mathrm{x}_{2}$ & $\mathrm{x}_{3}$ & Resin, $(\mathrm{g})$ & Curing agent, $(\mathrm{g})$ & $\left.\mathrm{TiO}_{2(21 \mathrm{~nm}}+100 \mathrm{~nm}\right),(\mathrm{g})$ & $\mathrm{TiO}_{2(21 \mathrm{~nm})}(\mathrm{g})$ & $\mathrm{TiO}_{2}(100 \mathrm{~nm})(\mathrm{g})$ \\
\hline 1 & - & - & - & 14.898 & 8.939 & 1.896 & 1.138 & 0.758 \\
2 & + & - & - & 11.823 & 11.822 & 1.896 & 1.138 & 0.758 \\
3 & - & + & - & 14.442 & 8.665 & 4.741 & 2.845 & 1.896 \\
4 & + & + & - & 11.460 & 11.461 & 4.741 & 2.845 & 1.896 \\
5 & - & - & + & 14.898 & 8.939 & 1.896 & 1.706 & 0.190 \\
6 & + & - & + & 11.823 & 11.822 & 1.896 & 1.706 & 0.190 \\
7 & - & + & + & 14.442 & 8.665 & 4.741 & 4.267 & 0.474 \\
8 & + & + & + & 11.460 & 11.461 & 4.741 & 4.267 & 0.474 \\
\hline
\end{tabular}

The "reference" samples (unmodified, cured epoxy resins) were prepared by adding appropriate amounts of hardener to the epoxy resin followed by mixing. The sample 01 contained $60 \mathrm{phr}$ of PAC hardener, while sample 02 contained $100 \mathrm{phr}$ of hardener. The curing time of the samples in the molds was 4 days at room temperature and then post-cured at $70{ }^{\circ} \mathrm{C}$ for $72 \mathrm{~h}$. The samples for ablative tests were prepared under laboratory conditions. A total of 20 composite samples with dimensions of $12 \times 35 \times 26 \mathrm{~mm}$ were prepared for the tests.

\subsection{Ablative tests}

Composite samples were weighed and mounted on plasterboard shields on a stand designed for ablation research prior to ablation test. Next, in a test which lasted $t=120 \mathrm{~s}$, the samples were exposed to a stabilized stream of combustible gases (Fig. 2). The heat source was a burning of propane-butane mixture (65\% propane and $35 \%$ butane) with temperature of flammable gases above $1900{ }^{\circ} \mathrm{C}$. The flame was stabilized with an ablation gun (Fig. 2b), whose axis was set perpendicularly to the front surface of the sample $(26 \times 35 \mathrm{~mm})$. The gun nozzle was set at a distance of $30 \mathrm{~mm}$ away from the surface of the ablation surface. The above configuration of the ablation test stand allows stabilizing the flame, unifying the temperature on the ablation surface as well as ensuring the repeatability of results for all test samples.

During the tests, the following temperatures were measured and recorded on the measurement stand (Fig. 3):
1. The ablative surface $\mathrm{T}_{\mathrm{pa}}$ with a thermovision camera Thermo Tracer NEC H2640 at the 60th second of each test.

2. The ablative surface $\mathrm{T}_{\mathrm{pa}}(\mathrm{t})$ using an optical pyrometer OPTCT2MHCF by Optris $\mathrm{GmbH}$, set at an emissivity of $\varepsilon=0.95$ and featuring a continuous electronic recording of temperature variations using Compact Connect 1.7.3 software.

3. The rear sample wall surface $\mathrm{T}_{\mathrm{s}}(\mathrm{t})$ by means of TP204N (NiCrSi-NiSi) thermocouple by Czaki Thermo-Product using a measurement module USB-4718 by Advantech.

The temperature distribution on the ablation surfaces of the tested samples was recorded by using a thermovision camera. Figure 4 shows the results of temperature measurement on the surface for sample no. 8 , after $60 \mathrm{~s}$ of the ablative sample exposition to heat flow. The brightest area in the upper part of the sample (point A) corresponds to the highest temperature on the surface-equal to $961.5^{\circ} \mathrm{C}$. The darker areas (points B and C) correspond in turn to its lower values, $780.7{ }^{\circ} \mathrm{C}$ and $616{ }^{\circ} \mathrm{C}$. Further away from the hot spot of the sample, the lower temperature values. The position of the point $\mathrm{A}$ in the upper area of the sample is caused by the rising of the hot gas jet upwards.

The temperature of ablative surface (shown in Fig. 5) resulted from the heat transfer at boundary between gas and solid state material, the heat conduction through the wall of the composite and the ablative processes taking place on surface layer (endothermic chemical reactions, polymer degradation and different structural changes). The value of this temperature depended on physical properties of solid 

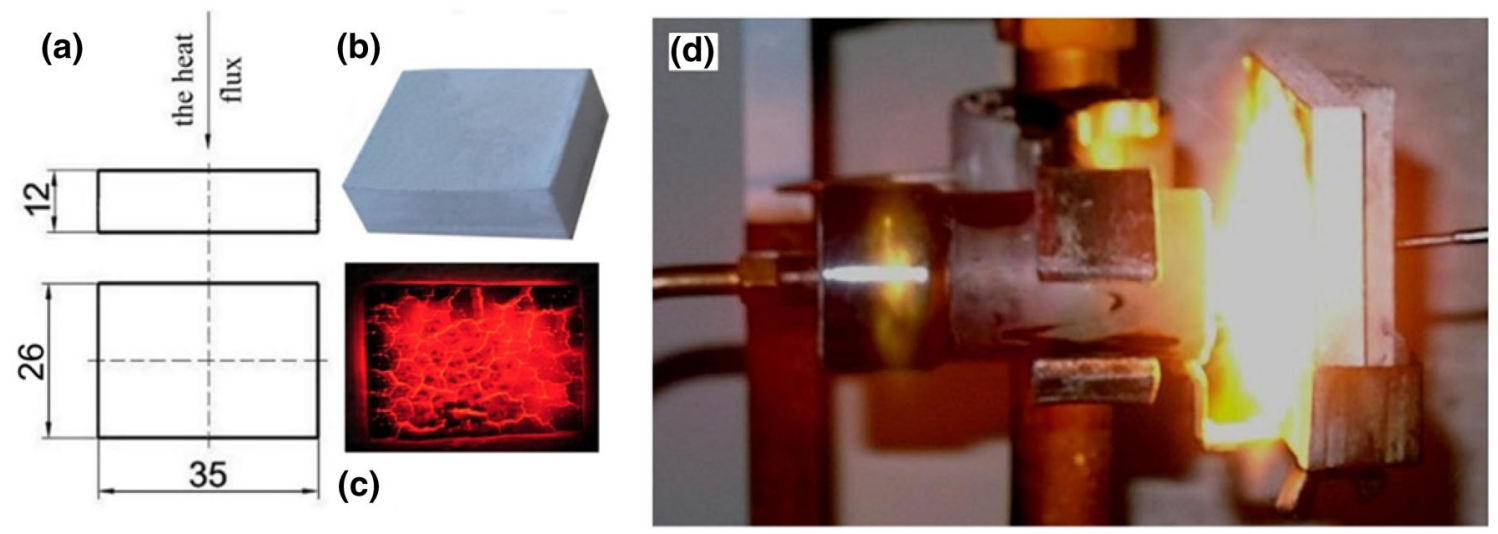

Fig. 2 The tested samples: a size and direction of the exposition of the heat flow, $\mathbf{b}$ the shape, $\mathbf{c}$ at the moment after ablative test, d during the test with the ablative gun

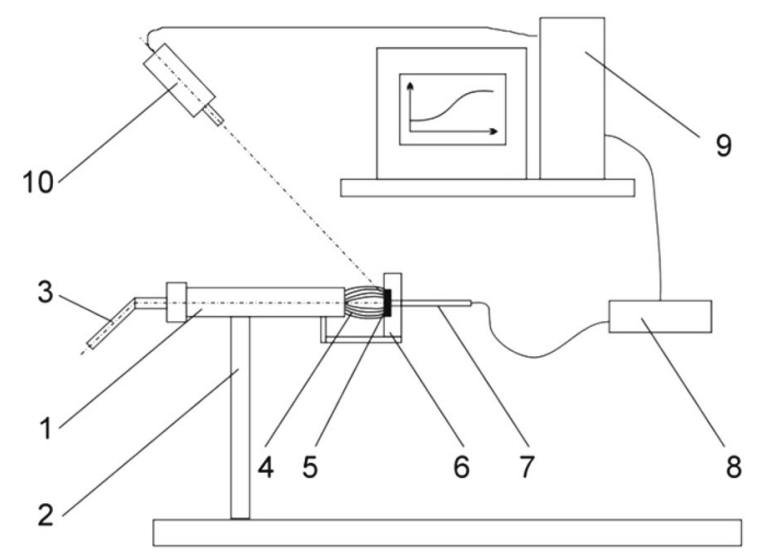

Fig. 3 Measurement stand: (1) the ablative gun with flammable gases stabilization, (2) a tripod, (3) a torch, (4) a flame, (5) the testing sample, (6) a sample casing, (7) the thermocouple, (8) the temperature measurer of $T_{s}(t)$, (9) a computer, (10) the pyrometer or the thermovision camera to $T_{p a}(t)$ measurement

material and gas, as well as insulating wall geometry. Ablative surface temperature $T_{p a}$ was considered as an indirect input testing parameter and was assumed as first type boundary condition for Dirchlet (determined by the temperature distribution anytime on the surface of the body), enabling in the future the resolution of Fourier Kirchhoff differential equation of unsteady heat conduction in solids (Kucharczyk 2007; Bakar et al. 2016). The average value of all measured maximum temperature $T_{p a \_ \text {max }}$ was $875{ }^{\circ} \mathrm{C}$ with a standard deviation of $14{ }^{\circ} \mathrm{C}$ (Fig. 6).

The temperature values obtained on the surface of the rear wall $T_{S_{-} \max }$ depend upon the possibility of using the material as a protective shield for a wide range of applications. The temperature of the surface on the rear wall $T_{s}(t)$ was measured for a period of 120 s. Figure 7 shows the temperature curves on the surface of the rear wall of the samples for each tested ablative composite.

The highest temperature $T_{S_{-} \max }$ of unmodified epoxy resin crosslinked with 100 phr of PAC hardener (composition no. 2) was almost three times higher than that of epoxy composite samples. During the last seconds of the test, the sample was destroyed as recorded by a sharp increase in temperature on its back surface (Fig. 7). However, the reduction of the hardener content to $60 \mathrm{phr}$ (composition no 1) resulted in decrease of $T_{s_{\_} \max }$, which still remained almost $30 \%$ higher than for the epoxy nanocomposites (Figs. 7 and 8).

Resin Epidian 52 modified with a nanofiller showed better thermo-protective properties. The epoxy composite no. 1 based on $60 \mathrm{phr}$ of hardener PAC, with a content of $2 \%$ by weight of a mixture of titanium dioxides, including $60 \%$ by weight $\left.\mathrm{TiO}_{2(21} \mathrm{nm}\right)$, reached the lowest temperature $T_{S_{-} \max }$ from all tested composites.

The histograms of temperature changes $T_{p a}(t)$, for samples from unmodified resins (compositions no. 1 and no. 2), are well below the graphs for epoxy nanocomposites (Fig. 5). Under fixed conditions, the heat transfer between gas and solid depends on the resistance of heat transfer $r_{k p}$, i.e. the value that include the physical properties of the material and gas with the geometry of the insulating wall. Thus, from the analysis of histograms temperature $T_{p a}(t)$, and $T_{s}(t)$ (Figs. 5 and 7), it follows that the lower 
Fig. 4 Example of the temperature field on the ablative surface after $60 \mathrm{~s}$ of the ablative sample exposition the heat flow (sample no. 8)

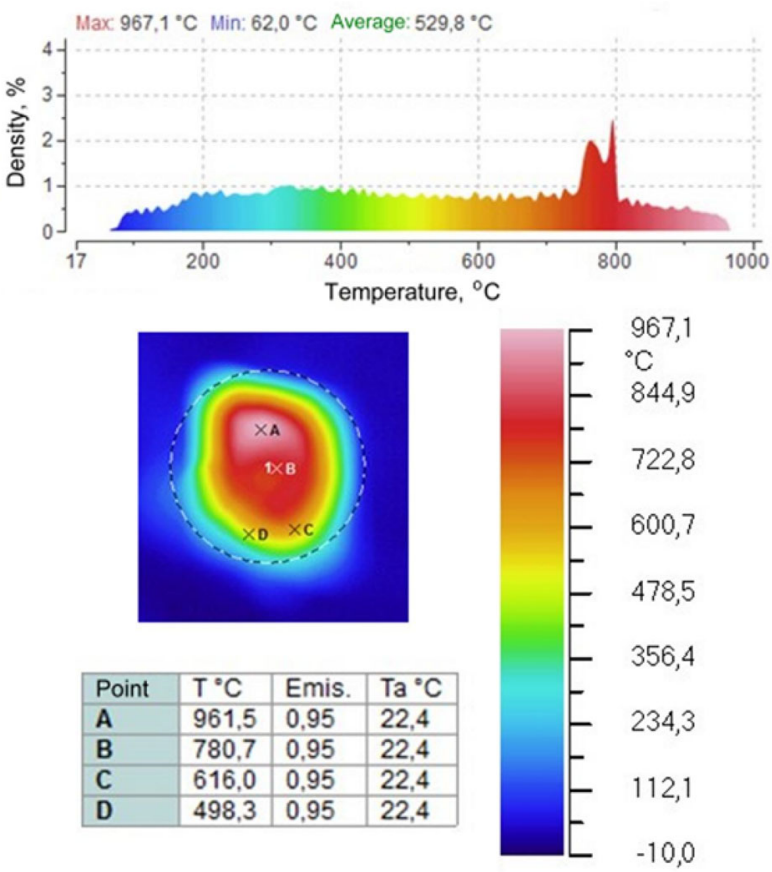

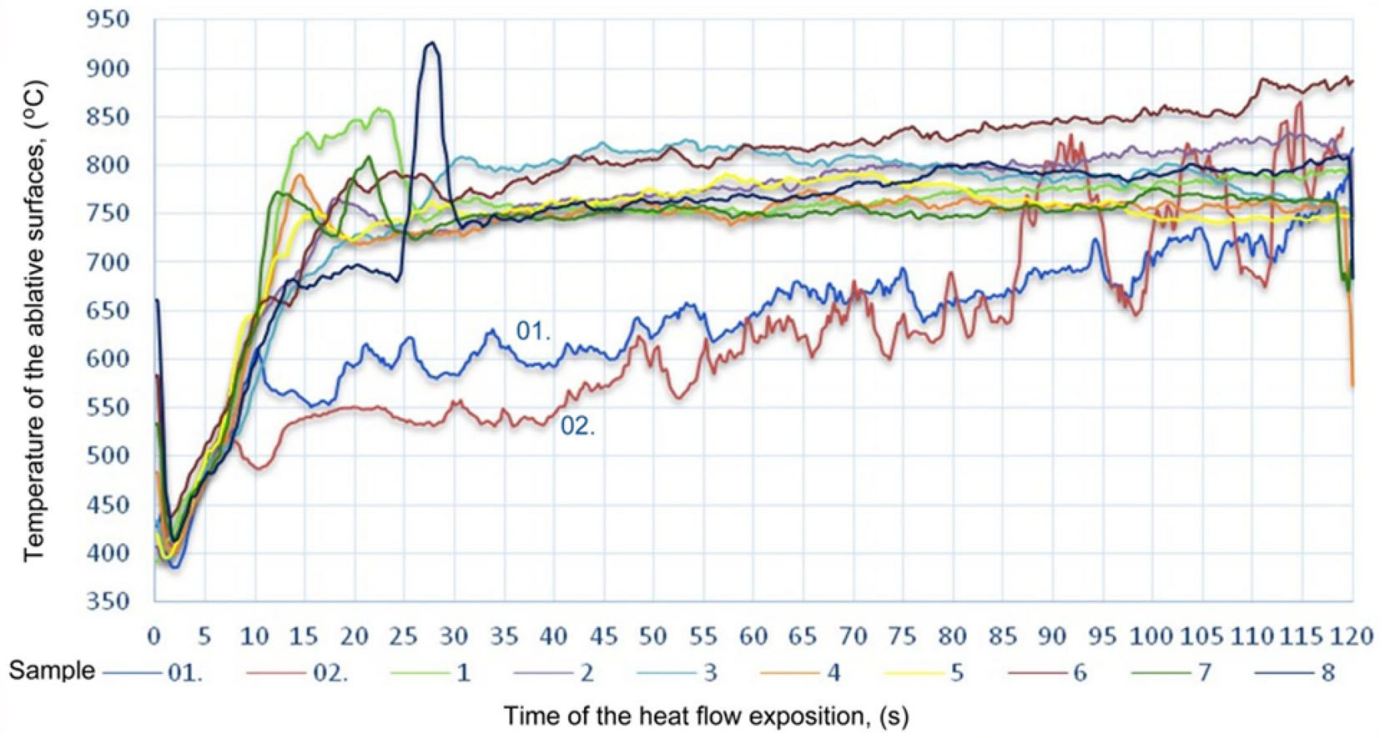

Fig. 5 Temperature on the ablative surfaces $\mathrm{T}_{\mathrm{pa}}(\mathrm{t})$ during $120 \mathrm{~s}$ of the heat flow exposition

temperature of the ablation surface $T_{p a}$ is due to higher rates of heat transfer at the border gas-solid, and thermal conduction through the wall of the composite, which is equivalent to an increase in the temperature of the rear face of the wall $T_{s}$ of a given material and depends directly on its phase composition. The greatest degree of reduction in temperature difference or $T_{p a}(t)-T_{s}$, the characterized nanocomposite epoxy compositions no 1 and no 8 . According to the laws of Pécelta have the greatest resistance to heat transfer replacement $r_{k p}$ of the test materials. From the point of view of thermo-protecting properties, it is important that the temperature of the rear surface of the wall $T_{s}$ of the ablative shield (s) is the lowest after a 


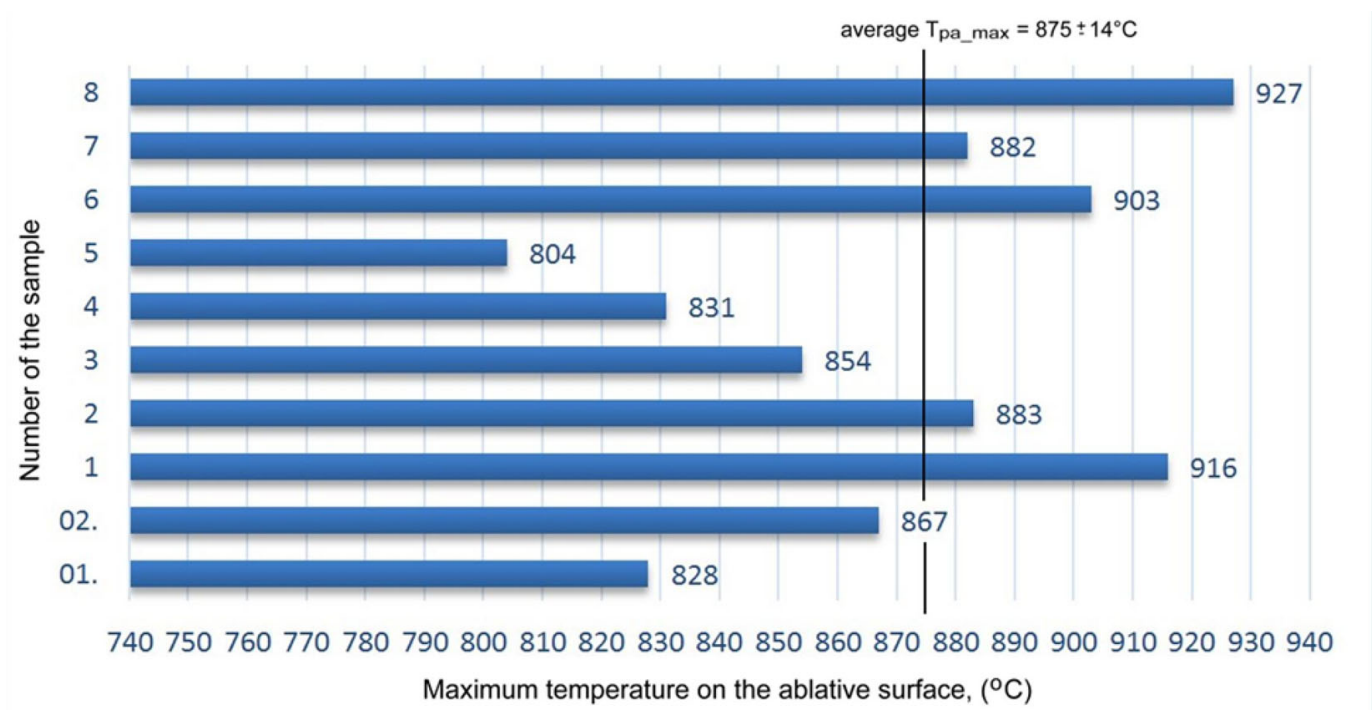

Fig. 6 Average maximum temperature on the surface of ablation $\mathrm{T}_{\mathrm{pa} \_ \text {max }}$ for particular phase compositions after $120 \mathrm{~s}$ of the heat flow exposition

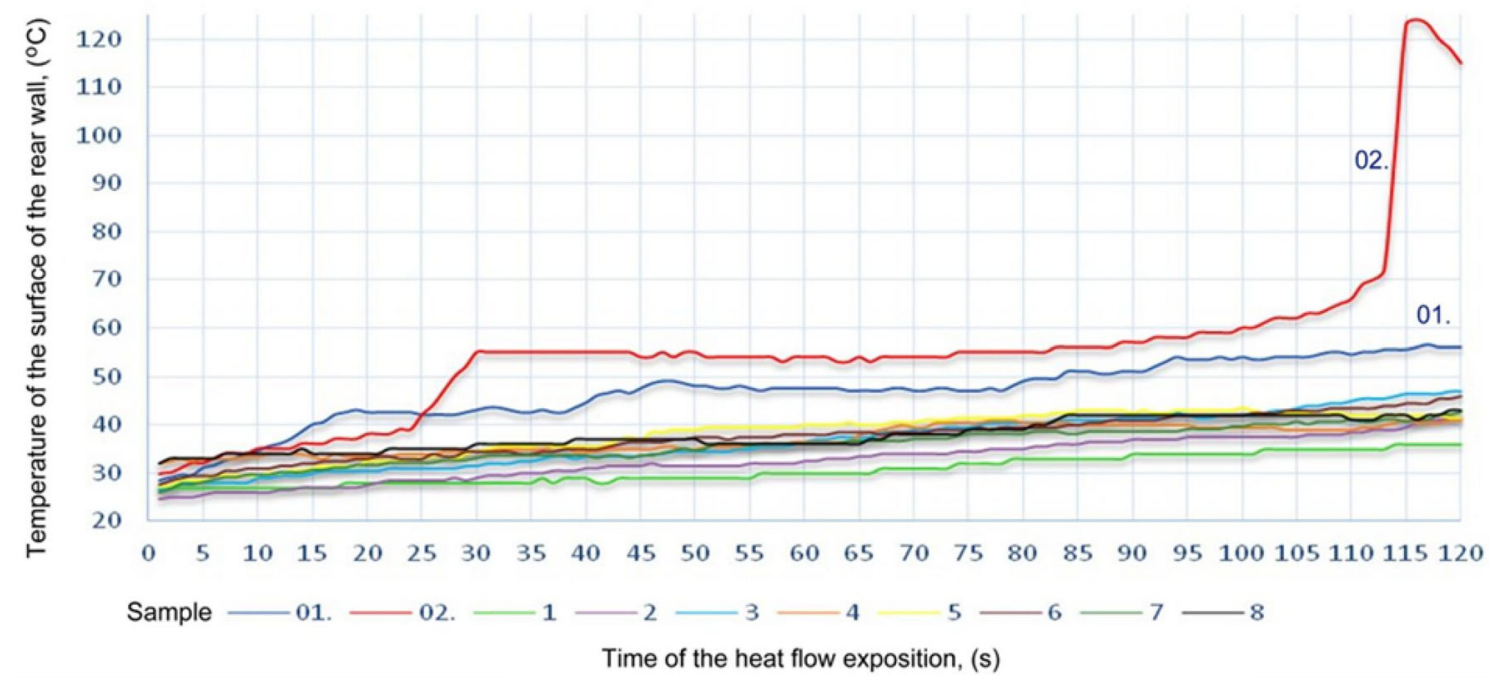

Fig. 7 Changing of the rear surface temperature $T_{s}(t)$ during $120 \mathrm{~s}$ of the heat flow exposition

given time of exposure to the heat flux. However, composites with a higher temperature on the ablation surface and a lower temperature on the back surface of the sample wall (higher temperature gradient) are subjected to higher thermo-mechanical stresses, which can lead to the destruction of the ablation shield (Kucharczyk 2010).

In this context, the ablation (erosive) weight loss of the $U_{a}$ composite becomes more important. The smaller loss of mass of the ablation layer, indicates higher thermal stability of the composite and a thicker operating top layer (Kucharczyk 2010) with a low thermal conductivity coefficient $\lambda(t)$. The smallest erosive wear after $120 \mathrm{~s}$ during the impact of the stream of combustible gas, the composition of the sample has suffered phase no 4 (Table 4 ), which is characterized by a second in order $T_{s_{-} \max }$ low temperature (Fig. 9).

The average values of ablative results of the tests (i.e. the maximum surface temperature of the ablation 


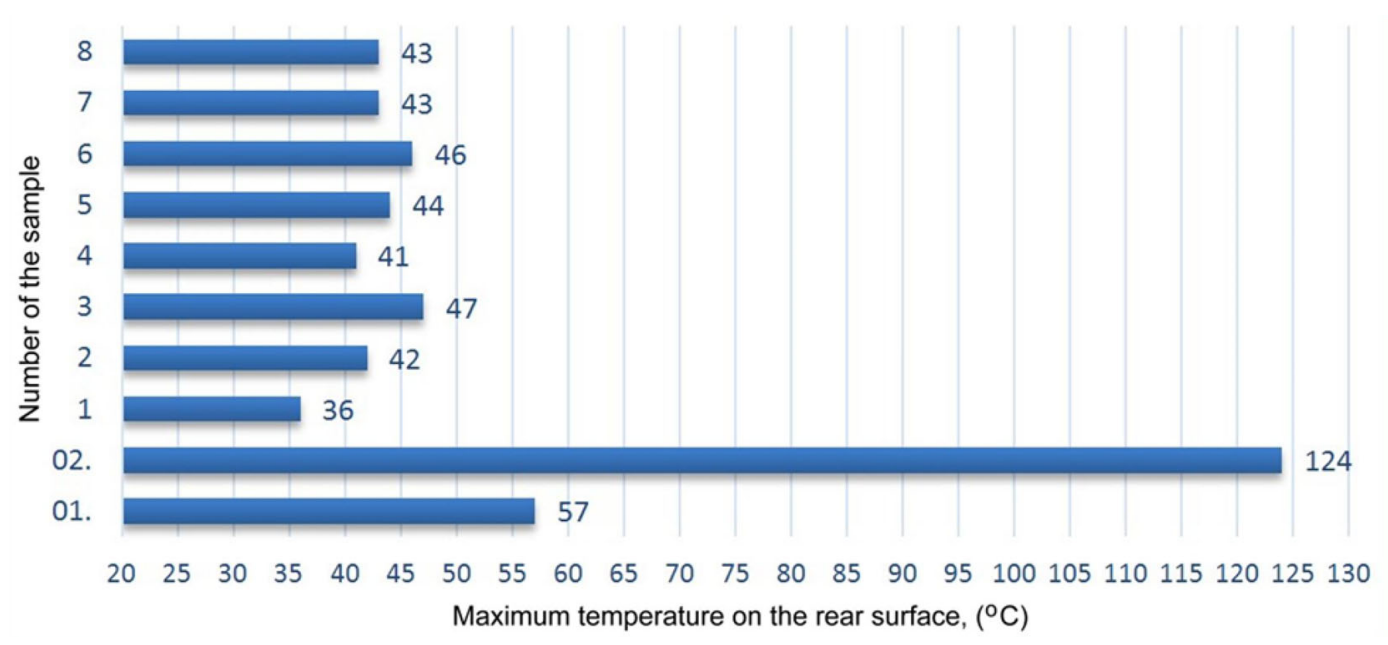

Fig. 8 Average maximum temperature on the rear surface $T_{s_{\_} \text {max }}$ for particular phase compositions after $120 \mathrm{~s}$ of the heat flow exposition

Table 4 Results of thermal protective tests after $120 \mathrm{~s}$ of treatment with hot combustion gases

\begin{tabular}{lllllllllll}
\hline Parameter & \multicolumn{1}{l}{ Number of specimen, no. } \\
\cline { 2 - 10 } & 01 & 02 & 1 & 2 & 3 & 4 & 5 & 6 & 7 & 8 \\
\hline $\mathrm{T}_{\mathrm{pa} \_\max }\left({ }^{\circ} \mathrm{C}\right)$ & 828 & 867 & 916 & 883 & 854 & 831 & 804 & 903 & 882 & 927 \\
$\mathrm{~T}_{\mathrm{s} \_\max }\left({ }^{\circ} \mathrm{C}\right)$ & 57 & 124 & 36 & 42 & 47 & 41 & 44 & 46 & 43 & 43 \\
$\mathrm{U}_{\mathrm{a}}(\%)$ & 65.2 & 90.7 & 67.1 & 58.8 & 37.7 & 34.0 & 47.7 & 65.3 & 38.8 & 37.1 \\
\hline
\end{tabular}

$T_{\text {pa_max }}$, the maximum temperature of the back surface area of an ablative sample $T_{s \_ \text {max }}$ and ablative weight loss $U_{a}$ ) are shown in Table 4 .

The lower weight loss is exhibited by composites containing a higher amount of nanofillers, i.e. $5 \% \mathrm{wt}$. no. 3 , no. 4 , no. 7 and no. 8 (Fig. 9). Samples no 4 and no 8 were cross-linked with a higher amount of hardener (100 phr). The smallest weight loss (34\%) was shown by the composite no. 4 , which contained less $\mathrm{TiO}_{2(21 \mathrm{~nm})}$, than composite no. 8. The sample "reference" no 2, cross-linked (similarly to composite no. 4) $100 \mathrm{phr}$ of hardener PAC, reached the largest ablation fat loss, up to about $90 \%$. This indicates the adverse effect of a larger amount of PAC hardener on the thermal stability and thermo-protective ablative properties of pure, unmodified Epidian 52 epoxy resin.

Epoxy composites have undergone intensive decomposition and pyrolysis during the ablation process with harmful volatiles products to human health. The formed ablative layer during the process was not consistent but brittle, very porous and automatically separated from the original material (Fig. 10). This constituted a negative phenomenon, which reduced both the strength and durability of coatings and their thermal protective characteristics.

Composites based on epoxy resins have undergone intensive decomposition and pyrolysis during the ablation process with harmful volatiles products to human health. The formed ablative layer during the process was not consistent but brittle, very porous and automatically separated from the original material (Fig. 10). This constituted a negative phenomenon, which reduced both the strength and durability of coatings and their thermal protective characteristics.

In summary, the smallest weight loss $U_{a}$ is characterized by a composite no. 4 (i.e. Epidian $52+100$ phr $\mathrm{PAC}+5 \%$ by volume of $\mathrm{TiO}_{2(21 \mathrm{~nm})}$ and $\left.\mathrm{TiO}_{2(100 \mathrm{~nm}}+1 \% \mathrm{Mn}\right)$, including $60 \mathrm{wt} \%$ of $\mathrm{TiO}_{2(21 \mathrm{~nm})}$.

The lowest end temperature of the back wall surface of the sample $T_{S_{-} \max }$ was obtained by the composite sample no. 1 with the following composition: Epidian $52+60 \mathrm{phr}$ PAC $+2 \%$ by volume of 


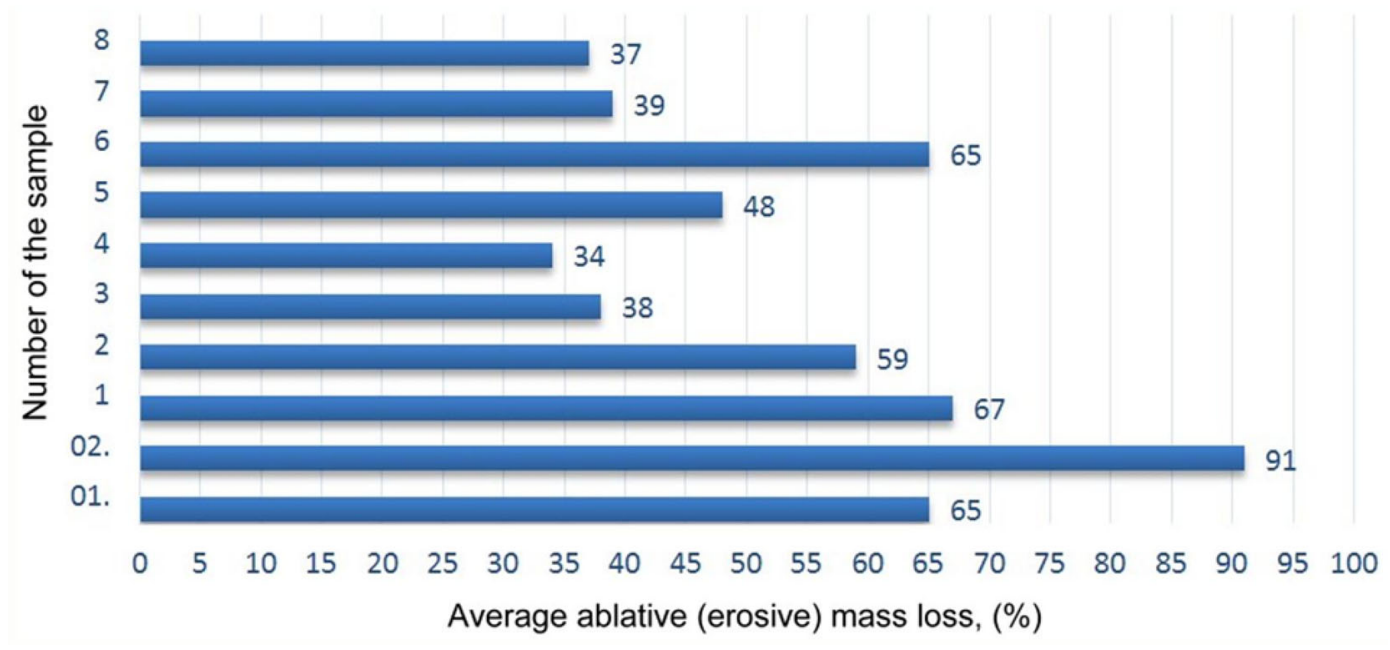

Fig. 9 Average ablative (erosive) mass loss $\mathrm{U}_{\mathrm{a}}$ after $120 \mathrm{~s}$ of the heat flow exposition

$\mathrm{TiO}_{2(21 \mathrm{~nm})}$ and $\left.\mathrm{TiO}_{2(100} \mathrm{nm}+1 \% \mathrm{Mn}\right)$, including $60 \mathrm{wt} \%$ of $\mathrm{TiO}_{2(21 \mathrm{~nm})}$.

The best thermoprotective properties were exhibited by the composite which reached the lowest value of the maximum surface temperature of the sample wall $T_{S_{-} \max }$ (provides the greatest temperature reduction) and the smallest ablation weight loss $U_{a}$ (has the highest thermal stability and is the thickest and most consistent internally, good adhesion to the original, ablative material exploitation layer with low thermal conductivity). Both conditions are best met by a sample with phase composition no 4 .

\section{Statistical analysis of the results}

Statistical calculations of both the component response functions $T_{s \_ \text {max }}\left(x_{i}\right)$ and $U_{a}\left(x_{i}\right)$ were conducted using the results of ablative testing. Table 5 shows the calculated values of regression coefficients $b_{i}$ and variance $s(y)$, errors of regression coefficients $s\left(b_{i}\right)$, and significance levels of regression coefficients $b_{i s t o t}$. The parameter $b_{i}$ is shown in bold-it is lower than $b_{\text {sign }}$ but subject to error $s\left(b_{i}\right)$ which, once taken into account to compute $b_{i}$, helps to estimate the sum total of $b_{i}$ and $s\left(b_{i}\right)$ as larger than $b_{i s t o t}$, that is, still significant statistically (Montgomery 2009; Leszek 1997).

Based on the calculated coefficients of regression and interaction $\left(b_{i}\right)$ and considering level of their significance $\left(b_{\text {sign }} \geq b_{i}\right)$, regression equations of the component response functions (2) and (3) are formulated:

$$
\begin{aligned}
T_{s \_ \text {max }}\left(x_{i}\right)= & \left(42.56+\mathbf{0 . 8 1} x_{2}\right. \\
& +1.19 x_{3}-1.69 x_{1} x_{2}-1.81 x_{2} x_{3} \\
& \left.+1.19 x_{1} x_{2} x_{3}\right) \pm 1.34{ }^{\circ} \mathrm{C} \\
U_{a}\left(x_{i}\right)= & \left(48.31-11.41 x_{2}+3.49 x_{1} x_{3}-2.99 x_{1} x_{2} x_{3}\right) \\
\pm & 4.73 \%
\end{aligned}
$$

Analysis of numerical results of statistical calculations for the maximum back side temperature of tested samples $T_{s_{\_} \max }$ are presented in Table 5 and coefficients of response function $T_{s_{-} \max }\left(x_{i}\right) \mathrm{Eq}$. (2) indicates the following rules:

1. A significant effect on decreasing the temperature of the back surface of the sample wall $T_{S}$ has two input variables $x_{2}$ and $x_{3}$ (negative coefficient $b_{23}$ ). They determine respectively: the content of the mixture of $\mathrm{TiO}_{2(21 \mathrm{~nm})}+\mathrm{TiO}_{2(100 \mathrm{~nm}+1 \% \mathrm{Mn})}$ in the composite and the amount of $\mathrm{TiO}_{2(21 \mathrm{~nm})}$ in the filler mixture. Increasing the number of nanofillers with a higher $\mathrm{TiO}_{2(21 \mathrm{~nm})}$ content in the mixture resulted in the reduction of the maximum temperature $T_{s \_}$max. This interaction does not occur when using a larger amount of hardener (changing the sign to positive at the $b_{123}$ coefficient).

2. Simultaneous application of larger quantities of hardener and a mixture of nanofillers, resulted in a 


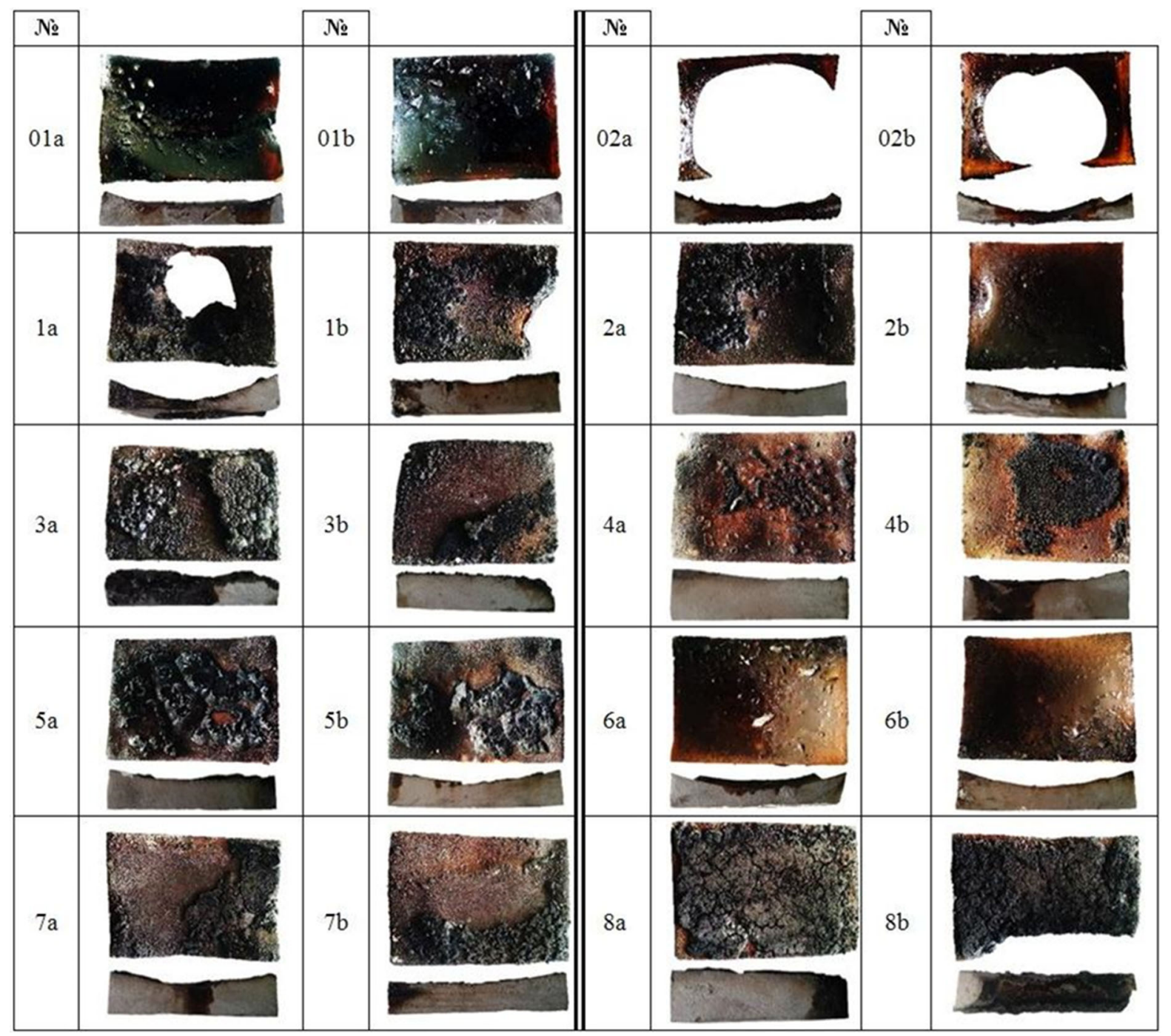

Fig. 10 The ablative surfaces and the mass waste of composites after $120 \mathrm{~s}$ of heat flux exposition

Table 5 Regression and interaction coefficients of model (1) after $120 \mathrm{~s}$ of ablative tests

\begin{tabular}{|c|c|c|c|c|c|c|c|c|c|c|c|}
\hline & $\mathrm{b}_{0}$ & $\mathrm{~b}_{1}$ & $\mathrm{~b}_{2}$ & $\mathrm{~b}_{3}$ & $b_{12}$ & $\mathrm{~b}_{13}$ & $\mathrm{~b}_{23}$ & $b_{123}$ & $\mathrm{~s}(\mathrm{y})$ & $\mathrm{s}\left(\mathrm{b}_{\mathrm{i}}\right)$ & $\mathrm{b}_{\text {sign }}$ \\
\hline $\mathrm{T}_{\mathrm{s}_{-} \max }\left({ }^{\circ} \mathrm{C}\right)$ & 42.56 & & 0.81 & 1.19 & -1.69 & & -1.81 & 1.19 & 1.34 & 0.47 & 1.09 \\
\hline $\mathrm{U}_{\mathrm{a}}(\%)$ & 48.31 & & -11.41 & & & $\mathbf{3 . 4 9}$ & & -2.99 & 4.73 & 1.67 & 3.86 \\
\hline
\end{tabular}

lower $T_{S_{\_} \max }$ temperature. This is evidenced by the negative value of the interaction factor $b_{12}$.

3. Increasing the content of fine-grained oxide $\mathrm{TiO}_{2(21 \mathrm{~nm})}$ (without increasing the amount of mixture of oxides and hardener content) will increase the temperature $T_{S_{-} \max }$ (positive coefficient $b_{3}$ ).

4. Input variable $\mathrm{x} 2$, denoting the amount of $\left.\mathrm{TiO}_{2(21 \mathrm{~nm})}+\mathrm{TiO}_{2(100 \mathrm{~nm}}+1 \% \mathrm{Mn}\right)$, in the individual interaction (without taking into account the 
amount of hardener and composition of the nanopowder mixture), does not significantly affect the temperature of the back surface of the sample wall.

Analysis of numerical results of statistical calculations for the ablative weight loss of test samples $U_{a}$ presented in Table 5 and coefficients of response function $U_{a}\left(x_{i}\right) \mathrm{Eq}$. (3) indicates the following rules:

1. The input variable $x_{2}$ (negative value of the coefficient $b_{2}$ ) has the most important influence on the ablation reduction of $U_{a}$ parameter, which means that increasing the amount of $\mathrm{TiO}_{2(21 \mathrm{~nm}) \text { - }}$ $\left.+\mathrm{TiO}_{2(100} \mathrm{nm}+1 \% \mathrm{Mn}\right)$ decreases ablation weight loss. The value of coefficient $b_{2}$ is over three times higher than the coefficients $b_{13}$ and $b_{123}$.

2. Input variables $x_{1}$ and $x_{3}$, denoting the amount of hardener and $\mathrm{TiO}_{2(21 \mathrm{~nm})}$ in the mixture of nanofillers, in mutual interaction (positive value of $b_{13}$ ), as well as the interaction of all three variables (negative value $b_{123}$ ) do not significantly affect the value of the response function $U_{a}\left(x_{i}\right)$. In addition, the opposite signs, with both of these coefficients, indicate the mutual abolition of influence.

\section{Conclusions}

Based on obtained results, it can be concluded that:

1. The composite based on epoxy resin Epidian 52 cross-linked with $60 \mathrm{phr}$ of PAC hardener, with a $2 \%$ by volume of a mixture of $\mathrm{TiO}_{2(21 \mathrm{~nm})-}$ $\left.+\mathrm{TiO}_{2(100} \mathrm{nm}+1 \% \mathrm{Mn}\right)$, including $60 \%$ by weight of $\mathrm{TiO}_{2(21 \mathrm{~nm})}$ ), characterized by the lowest temperature of the rear wall surface.

2. Epoxy resin Epidian 52 cross-linked with $100 \mathrm{phr}$ of PAC hardener, with $5 \%$ by volume of a mixture of nanofillers $\left.\mathrm{TiO}_{2(21 \mathrm{~nm})}+\mathrm{TiO}_{2(100 \mathrm{~nm}}+1 \% \mathrm{Mn}\right)$, including $60 \mathrm{wt} \%$ of $\mathrm{TiO}_{2(21 \mathrm{~nm})}$ ), shows the smallest abrasive weight loss $U_{a}$, i.e. the best thermal stability of the virgin material and cohesion of the ablative layer, which improves the resistance to thermomechanical stresses of the composite and ensures the formation of a passive thermo-protective layer.
3. Increasing the amount of PAC hardener in Epidian 52 resin-based composites and increasing the amount of both $\mathrm{TiO}_{2(21 \mathrm{~nm})}$ and $\mathrm{TiO}_{2(100 \mathrm{~nm}}+1 \%$ $\mathrm{Mn}$ ) led to increase of the maximum temperature of the back wall surface $T_{s_{-} \max }$ but at the same time contributed to the reduction of ablative weight loss $U_{a}$.

4. Considering the values of both parameters $\left(T_{s_{\_} \max }\right.$ and $U_{a}$ ), it should be noted that the best thermal protection properties were shown by composite no. 4, which was characterized by a very low, maximum temperature of the wall surface of the sample $T_{s_{\_} \max }\left(40{ }^{\circ} \mathrm{C}\right)$ as well as the lowest value of ablation weight loss $U_{a}(35 \%)$.

5. Epidian 52 epoxy resin composites crosslinked with PAC hardener and modified with $\left.\mathrm{TiO}_{2(21} \mathrm{nm}\right)$ $\left.\mathrm{i} \mathrm{TiO}_{2(100 \mathrm{~nm}}+1 \% \mathrm{Mn}\right)$ showed better thermo-protective properties compared to virgin unmodified epoxy resins.

Open Access This article is distributed under the terms of the Creative Commons Attribution 4.0 International License (http:// creativecommons.org/licenses/by/4.0/), which permits unrestricted use, distribution, and reproduction in any medium, provided you give appropriate credit to the original author(s) and the source, provide a link to the Creative Commons license, and indicate if changes were made.

\section{References}

Al-Ajaj, I.A., Abd, M.M., Jaffer, H.I.: Mechanical properties of micro and nano $\mathrm{TiO}_{2}$ /epoxy composites. IJMMME, 1 (2013), ISSN 2320-4060

Anselme, P.: Titanium dioxide. Titanium Dioxide Manufacturers Association (2013). http://www.cristal.com

Bahramian, A.R., Kokabi, M.: Ablation mechanism of polymer layered silicate nanocomposite heat shield. J. Hazard. Mater. 166, 445-454 (2009). https://doi.org/10.1016/j. jhazmat.2008.11.061

Bahramian, A.R.: Effect of external heat flux on the thermal diffusivity and ablation performance of carbon fiber reinforced novolac resin composite. Iran. Polym. J. 22, 579-589 (2013). https://doi.org/10.1007/s13726-0130157-z

Bakar, M., Kostrzewa, M., Białkowska, A., Pawelec, Z.: Effect of mixing parameters on the mechanical and thermal properties of nanoclay modified epoxy resin. High Perform. Polym. 26, 299-306 (2014)

Bakar, M., Kucharczyk, W., Stawarz, S.: Investigation of thermal and ablative properties of modified epoxy resins. Polym. Polym. Compos. 24, 617-623 (2016) 
Bakar, M., Szymańska, J., Rudecka, J., Fitas, J.: Effect of reactive diluents and kaolin on the mechanical properties of epoxy resin. Polym. Polym. Compos. 18, 503-510 (2010)

Bowers, J.: Nano titanium dioxide (2012). http://www.eoearth. org/view/article/154762

Chang, L., Zhang, Z., Breidt, C., Friedrich, K.: Tribological properties of epoxy nanocomposites. I. Enhancement of the wear resistance by nano- $\mathrm{TiO}_{2}$ particle. Wear 258, 141 (2005)

Chatterjee, A., Islam, M.S.: Fabrication and characterization of $\mathrm{TiO}_{2}$ - epoxy nanocomposite. Mater. Sci. Eng, A 487, 574-585 (2008)

Chen, X.B., Mao, S.S.: Titanium dioxide nanomaterials: synthesis properties, modifications, and applications. Chem. Rev. 107, 2891-2959 (2007)

Ciech-Sarzyna Co.: Informative papers of products Nowa Sarzyna ( in Polish ) (2014). http://ciechgroup.com/produkty/

Czub, P., Bończa-Tomaszewski, Z., Penczek, P., Pielichowski, J.: The chemistry and the technology of epoxy resins (in Polish). Scientifically-Technical Publishing House WNT, Warszawa (2002)

Dimitrienko, YuI: Thermomechanical behaviour of composite materials and structures under high temperature: 1. Mater. Compos. A 28a, 453-461 (1997). https://doi.org/10.1016/ S1359-835X(96)00144-3

Fujishima, A., Zhang, X.: Titanium dioxide photocatalysis: present situation and future approaches. C R Chimie 9, 750-760 (2006)

Haack, A.: Latest achievements and perspectives in tunnel safety. Tunn. Undergr. Space Technol. 19, 305 (2004). https://doi.org/10.1016/j.tust.2004.01.007

Hassanzadeh-Aghdam, M.K., Ansari, R.: Thermomechanical investigation of unidirectional carbon fiber-polymer hybrid composites containing CNTs. Int. J. Mech. Mater. 14, 1-18 (2018)

Hsieh, T.H., Kinloch, A.J., Masania, K., Taylor, A.C., Sprenger, S.: The mechanisms and mechanics of the toughening of epoxy polymers modified with silica nanoparticles. Polymer 51, 6284-6294 (2010)

Hu, Y., Tsai, H.L., Huang, C.L.: Effect of brookite phase on the anatase-rutile transition in titania nanoparticles. J. Eur. Ceram. Soc. 23, 691-696 (2003)

Jackowski, A.: Ablation flat wall erosion under floating layer ablation (in Polish). Biuletyn WAT 460, 23-33 (1986)

Kucharczyk, W.: Ablative and abrasive wear of phenolicformaldehyde glass laminates with powder fillers. Eksploatacja i Niezawodnosc 14, 11-17 (2012)

Kucharczyk, W.: Some ablative properties of epoxy composites used for thermoprotection (in Polish). Przemysł Chemiczny 89, 1673-1676 (2010)

Kucharczyk, W., Dusiński, D., Żurowski, W., Gumiński, R.: Effect of composition on ablative properties of epoxy composites modified with expanded perlite. Compos. Struct. 183, 654-662 (2018). https://doi.org/10.1016/j. compstruct.2017.08.047

Kucharczyk, W., Przybyłek, P., Opara, T.A.: Investigation of the thermal protection ablative properties of thermosetting composites with powder fillers: the corundum $\mathrm{Al} 2 \mathrm{O} 3$ and the carbon powder C. Pol. J. Chem. Technol. 15, 49-53 (2013). https://doi.org/10.2478/pjct-2013-0067
Kucharczyk, W.: Investigation of the thermal protection ablative properties of polymer composites with powder fillers (in Polish). Unpublished doctoral dissertation. Technical University of Radom, Radom (2007)

Leszek, W.: Empirical research. Some methodological issues [in Polish], 1st edn. Institute for Sustainable Technologies in Radom, Radom (1997)

Li, H., Wang, D., Chen, H., Liu, B., Gao, L.: The shielding effect of nano $\mathrm{TiO}_{2}$ on collagen under UV radiation. Macromol. Biosci. 3, 351-353 (2003)

Lin, W.S.: Steady ablation on the surface of a two-layer composite. Int. J. Heat Mass Transf. 48, 5504-5519 (2005)

Lombardi, M., Fino, P., Malucelli, G., Montanaro, L.: Exploring composites based on PPO blend as ablative thermal protection systems-Part I: the role of layered fillers. Compos. Struct. 94, 1067-1074 (2012). https://doi.org/10.1016/j. compstruct.2011.10.019

Merad, L., Benyoucef, B., Abadie, M.J.A., Charles, J.P.: Characterization and mechanical properties of epoxy resin reinforced with $\mathrm{TiO}_{2}$ nanoparticles. J. Eng. Appl. Sci. 6, 205-209 (2011)

Montgomery, D.C.: Design and analysis of experiments. Wiley, New York (2009)

NIST NCSTAR 1: Federal building and fire safety investigation of the world trade center disaster: final report on the collapse of the World Trade Center. U.S. Government Printing Office, Washington, September 2005. Retrieved Jun 12, 2006, from http://www.nist.gov/manuscript-publicationsearch.cfm?pub_id=909236

Ono, K., Otsuka, T.: Fire design requirement for various tunnels. In: 32nd ITA-World Tunnel Congress, Seoul, April 25th 2006. Retrieved Jun 23, 2006, from www.ita2006.com

Patton, R.D., JrCU, Pittman, Wang, L., Hill, J.R., Day, A.: Ablation, mechanical and thermal conductivity properties of vapour grown carbon fiber-phenolic matrix composites. Compos. A 33, 243-251 (2002). https://doi.org/10.1016/ S1359-835X(01)00092-6

Rajabi, L., Mohammadi, Z., Derakhshan, A.A.: Thermal stability and dynamic mechanical properties of nano and micron- $\mathrm{TiO}_{2}$ particles reinforced epoxy composites: effect of mixing method. Iran. J. Chem. Eng. 10, p (2013)

Rao, P.S., Mohana, KChK, Vijay, S.B.M., Govinda, R.P., Surya, P.A.: Synthesis of nano titanium dioxide powder using MWP (microwave plasma) and its characterization. IJMER 2, 1150-1156 (2012)

Sigma-Aldrich Co.: Informative papers of products. Titanium (IV) oxide (2014). http://www.sigmaaldrich.com

Song, G.M., Zhou, Y., Wang, Y.J.: Effect of carbide particles on the ablation properties of tungsten composites. Mater. Charact. 50, 293-303 (2003a). https://doi.org/10.1016/ S1044-5803(03)00123-2

Song, G.M., Zhou, Y., Wang, Y.J.: Thermomechanical properties of TiC particle reinforced tungsten composites for high temperature applications. Int. J. Refract. Metals Hard Mater. 21, 1-12 (2003b)

Szymańska, J., Bakar, M., Białkowska, A., Kostrzewa, M.: Study on the adhesive properties of reactive liquid rubber toughened epoxy-clay hybrid nanocomposites. J. Polym. Eng., Published online 09-11-2017. https://doi.org/10. 1515/polyeng-2017-0099 
Wetzel, B., Rosso, P., Haupert, F., Friedrich, K.: Epoxy nanocomposites-fracture and toughening mechanism. Eng. Fract. Mech. 73, 2375 (2006)

Wilkinson, T.: The World Trade Center and 9/11: the discussion of some engineering design issues. National Conference "Safe Buildings for This Century". Australian Institute of Building Surveyors, Sydney (2002)
Willam, K., Rhee, I., Shing, B.: Interface damage model for thermomechanical degradation of heterogeneous materials. Comput. Methods Appl. Mech. Eng. 193, 3327-3350 (2004). https://doi.org/10.1016/j.cma.2003.09.020

Yu, F.-Er.: Study on the ablation materials of modified polyurethane/polysiloxane. Unpublished doctoral dissertation. National Sun Yat-sen University, Materials Science and Engineering Department, Guangzhou (2004) 